\title{
LA CATALUNYA NOVA SEGONS UN MANUSCRIT INÈDIT DE LA CRÒNICA DEL MORO RASIS
}

\author{
M. Mercè Viladrich
}

El propòsit d'aquest escrit és fer conèixer un manuscrit inèdit que conté una versió castellana de la Crònica del moro Rasis.

Reproduiré, tot seguit, els quatre capítols d'aquest text que, dins la descripció geogràfica d'al-Àndalus, fan referència a la Catalunya Nova. Sense cap intenció de fer-ne una edició crítica, els compararé amb el text editat d'aquesta crònica segons el manuscrit de la biblioteca de la Catedral de Toledo ${ }^{1}$.

Enguany es compleix el mil·lenari de la destrucció de Barcelona per al-Mansūr ${ }^{2}$, que va suposar també la pèrdua de molta documentació que tal vegada ens hauria pervingut i hauria completat els fons de l'Arxiu de la Corona d'Aragó. Atès aquest fet i la tasca del

1 Ed. D. CATAl.AN y M.S. De ANDRÉs, Crónica del Moro Rasis, versión del ajbār mulūk al-andalus de ahmad ibn muhammad ibn mûsd̀ al-rãzi, 889-955, Madrid 1975.

2 Sobre la destrucció de Barcelona per al-Mansūr hi ha una publicació recent: P. CATALA I ROCA, El dia que Barcelona va morir (6 juliol 985); al-Mansur, ed. R. Dalmau, «Episodis de la Història», Barcelona 1984 pp. 256-257. 
Dr. Frederic Udina i Martorell al capdavant de la direcció d'aquest Arxiu i la seva recerca sobre la documentació comtal de Barcelo$\mathrm{na}^{3}$, he pensat d'aprofitar aquesta ocasió per fer conèixer aquest manuscrit, que conté un text historiogràfic andalusí i que ha sobreviscut molts anys perquè es conserva a la biblioteca-museu Víctor Balaguer, de Vilanova i la Geltrú4.

El manuscrit està catalogat amb el núm. 15. És de paper, amb 117 folis de $22 \times 17 \mathrm{~cm}$ i de 21 línies per pàgina. La lletra és del segle XVII, en tinta negra, a tota plana. La numeració dels folis, al marge superior esquerre, és en vermell, com també la majoria de lletres majúscules.

El text s'inicia al foli $1 a$, fent al-lusió explícita al manuscrit de l'església de Santa Catalina de Toledo, el que té més renom, i és per això que he escollit aquest text per fer-ne la comparació amb el de Vilanova i la Geltrú. El manuscrit $C a$ del segle XV presenta la descripció geogràfica d'al-Àndalus i la història pre-islàmica de la península de la Crònica del moro Rasis, segons la versió de Gil Pérez. Exclou, en canvi, la part relativa al regnat de Roderic, a la conquesta musulmana i a l'emirat. El text d'aquest manuscrit continua amb la Crónica sarracina (v. 1430) de Pedro de Corral, una novela històrica construïda a partir de la Crònica del moro Rasis. La Crónica Geral de España, de 1344, de Pedro de Barcelos, incorpora, als apartats que corresponen a la descripció geogràfica, la conquesta d'al-Àndalus i la història dels emirs. Alguns fragments d'aquest text es conserven en un manuscrit, avui a El Escorial, que hauria estat propietat d'Ambrosio de Morales 5 . El nostre manuscrit també al-ludeix a aquest text, car comença:

${ }^{3}$ Cf. F. Udina I MARToRelL, El Archivo Condal de Barcelona en los siglos IX y $x$. CSIC, Barcelona 1951.

${ }^{4}$ L'existència d'aquest manuscrit l'he coneguda per mițà de Pere Balañà, que va treballar en aquesta biblioteca, cf. «Los manuscritos árabes de la fundación Balaguer de Vilanova i la Geltrú (Barcelona)», Awrāq 2, 1979, pp. 22-24.

5 Cf. D. CATALÁN Y M.S. DE ANDRÉS, op. cit, pp. XII-XVII. 


\section{Descripcion de España}

con la entrada en ella de los Romanos y los Godos y los Moros escrita en arabigo por Rasis Moro que escrivio en el año de Cristo 972 [sic]. Traducido de Arabigo en Portugues por Gil Perez clerigo por mandado de Don Denis Rey de Protugal y despues de Portugues en Castellano por dos traducciones. Una que esta en el colegio Sta. Catalina de Toledo. Y de otro original de diferente traducción que tiene Ambrosio de Morales antiquissimo escrito en pergamino que antes que comiençe dize assi:

Comenzo a Reinar el Rey Don Alfonso que agora es en CastiIIa.

Añadida a esta traduccion lo que le falta del original de Sta. Catalina cuyo traslado es el que se sigue y esta oy en la Biblioteca de la Sancta Iglesia de Toledo.

A continuació segueix la descripció esmentada, amb els capítols finals de les serralades $\mathrm{i}$ els rius. Al foli 27 a s'inicia la segona part, amb la Historia de Romanos y Godos, la qual mereix més atenció que la que he de dedicar-li aquí, encara que el seu estudi probablement no aportaria cap novetat important a l'edició de D. Catalán i M. S. de Andrés.

Com ja he dit, he de centrar-me exclusivament en els capítols relatius a la zona d'al-Àndalus que la Corona d'Aragó va incorporar en la seva expansió, i que avui formen part de Catalunya: Tortosa, Tarragona i Lleida.

Abans de començar he d'indicar que la divisió de les frases segueix l'establerta a l'edició esmentada pel text $\mathrm{Ca}$. Aquesta divisió es pot seguir molt de prop fins a arribar al capítol descriptiu de les terres de Lleida. En aquest capítol he repetit la numeració per a ambdós textos, mantenint-hi l'ordre de les frases del text $\mathrm{Ca}$. 
Fol. $8 b$ in fine

1 En el termino de Valencia parte con el termino de Tortosa

2 y el Castillo de Tortosa es muy bien fecho a maravilla

3 yaze sobre el Rio de Ebro / puerto de mar donde entra este Rio

4 que Tortosa yaze contra levante que Valençia es contra el levante de Cordova

5 et Totosa es buen porto buen puerto,

6 y los mercaderes ban alli de todas las partes de la tierra

7 y es camino de los de Françia

8 ca ay ha muchas y buenas cosas que non ha en otra tierra

9 delas quales una es que ay mucho vox

10 de alli lo llevan a todas aquellas partes $^{6}$

11 et ay muchos arboles y los demas son pineros

12 y de Valençia a Tortosa ay ciento y cinquenta millares.
Parte el termino de Tortosa con el de Valençia;

e el de Tortosa esta bien bien fecho,

e esta sobre el rrio de Ebro, açerca donde entra este rrio en la mar E otrosy Tortosa yaze al leuante de Valençia e a levante de Cordoua.

E Tortosa ha muy buen termino $\mathrm{e}$

e los mercadores vienen y de toda la parte de la tierra, e es çerca de los de Françia.

$\mathrm{E}$ ay munchas buenas cosas que non ay en otras tierras, de las quales es la vna que a $y$ mucho box, e dende lo lievan a todas las partes del mundo: otrosi mucho açafran e muy bueno

E de Tortosa a Valençia ha çiento e çinquenta migeros, sy fueren por el camino de Martronia que es mas luengo quel de los fijos de Darache.

6 Ms.: «dealli lollevann. 
1 Parte el termino de Tortosa en el termino de Tarragona

2 es ciudad muy buena y poblada de los antiguos

3 et yaze sobre la mar

4 y vienen por alli un rrio de Galie que corre contra el sol levante y entra en el Rio de Ebro. Tortosa e Tarragona.

5 En Tortosa yaze corriente de los moros

6 et Tortosa al sol levante de de Cordova

7 en Tarragona yaze delante la çiudad de Tortosa

8 cade Barcelona a Tortosa a cinquenta millares de Tarragona. A Barcelona a çinquenta millares

9 et Tarragona fue de las villas

que fincaron de fundamentos viejos et fallan

ay rastro de Consoles antiguos

e maravillosos

que ay a Consoles

10 et ay edificados que senon $/ 9 b$ des fara por ningun tiempo

11 pero Azas le destruxo Tariphe el fijo de Mazair cuando entro en España

$12 \mathrm{ca} \mathrm{el}^{7}$ mato las gentes et destruyolos todos

13 mas no pudo a todos ca tanto es de firme
Parte el termino de Tastagosa con el de Tortosa.

E Tarragona es çibdat muy vieja $\mathrm{e}$ poblada de los antiguos.

E yaze sobre la mar.

e va a par della el rrio de Galian, que corre contra el sol levante e entra en el rrio de Ebro entre

E Tarragona yaze en el oriental de los moros.

E Tortosa e Tarragona yazen al levante de Cordova

E Tarragona yaze entre Tortosa e Barçelona, e a della a Tortosa çinquenta migeros.

E Tarragona fue de los logares mas antiguos que que fallan fundamientos muy viejos e muy maravillosos.

e a y cosas que se non desfazen por ningun tienpo.

meguer todas las destruyo Taris, fijo de Mazayr, quando entro en Espana, e el mato las gentes et destruyo las obras. mas non pudo todas, tanto las fizieron de firmes.

E Tarragona ha muy buen termino e fermoso e muy rregantio e conplido de munchos frutos.

7 Ms.: acaels. 
14 et de Tarragona a Zaragoza a çiento et cinquenta millas.

\section{Fol. $9 b$}

1 El termino de Zaragoza con el termino de Lerida ${ }^{8}$

2 yaze contra el Septentrion de Tarragona y contra el sol levante de Cordova

3 y yaze sobre el Rio de Sigura et sale este Rio de la sierra de Sigura

4 e quando fundaron la villa fallaron este Rio el termino Pilares

5 este Rio entra en un castillo que ha nombre Mazinece ${ }^{9}$

6 en este Rio sacan oro fino dan otros rrios.

7 y entra en este Rio otro Rio que ha nombre Bocario

8 y este et los otros Rios entran el Rio de Selvias que llaman.

9 Ilerda, ha villas y Castillos

10 los quales el uno es Caravinas

11 et Caravinas yaze sobre el Rio de Bocaria

12 et otro es un castillo que nombre ha Velcayre

13 y Velcayre yaze sobre el rio de Segura

14 el otro es Faraga

15 et Faraga yaze sobre el Rio de las Olivus

8 Paraula corregida al manuscrit.

9 Lectura conjectural.
E de Tarragona a Çaragoza ay çiento e çincuenta migeros.

Parte el termino de Lerida con el de Tarragona.

E Lerida yaze el sentrention de Tarragona, contra el sol levante de Cordoua;

e yaze sobre el rrio de Segre, e este rrio sale de la sierra de Segura.

E quando fundaron esta villa, toma este rrio enel termino de Pilares.

E este rrio entra en Ebro so vn castillo que ha nonbre Vicueça.

E este rrio da oro fino, lo que non

E entra en este rrio otro que ha nonbre Vocayra, e este e los otros rrios entran en el rrio de las Olivas que Ilaman. E Leridas ha villas e castillos en su termino muy buenos e muy conplidos de todas las cosas, de los quales es el vno

Carauinas. E Carauinas yaze sobre el mio de Bacayra.

E el otro es el castillo que ha nonbre Volcare.

E volcare yaze sobre el rrio de Segre.

E el otro es Fagra

E Fagra yaze sobre el rrio de las Oliuas: e Fraga ha muy buena vega de 
muchos e buenos arboles e muy

y el otro es un castillo que ha nombre Albyda Almotaxa

34 et de Almotaxa a Lerida ay treinta millares et de almotazen a Zaras / $10 a$ ha ochenta millas

Vallena,

conplido.

Lorivas.

España, las gentes que morrauan en buenos rregantios.

E el otro castillo ha nonbre Alcolea.

Alcolea yaze sobre este rrio de las

e a muy buenas vegas rregantias e

viñas,

c el es lugar muy plantado e bien

E el otro castillo es de Mocoues: es muy fuerte a maravilla e muy alto, e yaze sobre este rrio de las Olivas, $\mathrm{e}$ ha muy buenas vegas e muy bien

e es muy grant villa e muy buena e muy fermosa.

E el otro castillo ha nonbre Tabit, que es muy buen castillo.

E el otro que ha nonbre Pedro. que es muy bueno de panos.

E el otro que ha nonbre Abuyda, e Abuyda es muy fermoso castillo. E el otro castillo que ha nonbre Almontaxa (...) a Lerida e diez e nueve migeros.

E el otro castillo que ha nonbre

e es lugar muy plazentero e bien E el otro castillo que ha nonbre E el otro castillo ha nonbre Lasehen. E quando los moros entraton en

estos castillos fizieron pleytesia con los moros e fincaron en sus castillos, e los moros sin contienda. En su termino de Lerida yaze otro castillo que ha nonbre Ayqueaxe, e otro que ha nonbre Desamon. 
E quando Espana era de los moros, estos castillos estauan metidos en los fijados de los christianos, e los moros estauan todo el dia con ellos a las carreras.

44 y Lerida ha fundamentos antiEn Lerida ha fundamentos antiguos, guos

45 y es lugar muy nombrado villas e muchos castillos,

e es lugar muy noble e ha muchas

e nos tardariamos mucho si los

46

contasemos todos.

y en su termino ha un Castillo que ha nombre la Sege y quando los Moros entraron en España las gentes morayan en estos castillos trujeron pleitesia con los moros y fincaron con sus Castillos los moros con ellas $\sin$ contienda 10 . En su termino de Lerida

40 et a un Castillo que ha nombre Arrax

41 y otro que nombre Destibre

42 y quando esta España era de los moros estos Castillos yazian metidos enlos figados de los Christianos et los Aloros

43 estando cada dia los Aloros con ellos a barreras

47 y de Lerida a Zaragoza ay çien millas

48 et de Lerida a Barcelona ay otro tanto.

E de Lerida a Caragoça a çien migeros: de Lerida a Barçelona ha otros çien migeros.

10 La puntuació és meva. 